\title{
ANÁLISE ESPAÇO-TEMPORAL DA COBERTURA VEGETAL E USO DA TERRA NA INTERBACIA DO RIO PARAGUAI MÉDIO-MT, BRASIL ${ }^{1}$
}

Seyla Poliana Miranda Pessoa ${ }^{2}$, Edinéia Aparecida dos Santos Galvanin ${ }^{3}$, Jesã Pereira Kreitlow ${ }^{4}$, Sandra Mara Alves da Silva Neves ${ }^{5}$, Josué Ribeiro da Silva Nunes ${ }^{6}$ e Bruno Wagner Zago ${ }^{2}$

\begin{abstract}
RESUMO - O objetivo deste estudo foi realizar uma análise espaço-temporal da cobertura vegetal e do uso da terra na Interbacia do Rio Paraguai Médio-MT, Brasil, pelo geoprocessamento de imagens Landsat TM, dos anos 1991, 2001 e 2011. As imagens foram georreferenciadas, classificadas e processadas no software Spring e as classes temáticas, quantificadas e editadas no software ArcGis. Foram mapeadas sete classes, sendo as mais expressivas a vegetação nativa, a pastagem e a cana-de-açúcar. Os resultados indicaram alterações em todas as classes durante os últimos 20 anos, com a diminuição de 22,89\% da vegetação nativa, relacionada com o aumento de $58,42 \%$ da pastagem e $490,26 \%$ de monocultura de cana-de-açúcar. Foi verificado o conflito de uso da terra, principalmente em áreas de mata ciliar, fato que pode influenciar negativamente na conservação da interbacia e, consequentemente, do pantanal mato-grossense.
\end{abstract}

Palavras-chave: Espaço-temporal, Uso da terra, Sensoriamento remoto.

\section{SPATIO-TEMPORAL ANALYSIS OF VEGETATION COVER AND LAND USE IN THE MIDDLE PARAGUAY RIVER INTERBASIN-MT, BRAZIL}

\begin{abstract}
This study analyzed spatial and temporal land use changes in the Middle Paraguay River InterbasinMT, Brazil using Landsat images from 1991, 2001 and 2011. Images were geo-referenced, classified and processed using Spring software, and thematic classes were edited and quantified using ArcGis software. Seven map classes were identified, and native vegetation, pasture and sugarcane were the most significant ones. The results showed changes in all classes during the past 20 years, primarily a $22.89 \%$ decrease of native vegetation, a $58.42 \%$ increase in pasture and $490.26 \%$ increase of sugarcane monoculture. We verified land use conflicts, mostly in riparian areas, which may negatively influence Interbasin and, consequently, Pantanal conservation in the State of Mato Grosso, Brazil.
\end{abstract}

Keywords: Spatio-temporal, Land use, Remote sensing.

\section{INTRODUÇÃO}

Nas últimas décadas, a expansão da fronteira agrícola no Brasil vem ocupando, de forma desordenada, áreas de vegetação nativa, resultando na degradação, fragmentação e esgotamento dos recursos florestais (GREGGIO et al., 2009). As consequências desse quadro de degradação provocam efeitos negativos sobre a manutenção da biodiversidade (BIERREGAARD JÚNIOR et al., 1992), principalmente com a extinção de várias espécies

\footnotetext{
${ }^{1}$ Recebido em 19.09.2012 aceito para publicação em 20.12.2012

${ }^{2}$ Programa de Pós-Graduação em Ambiente e Produção de Sistemas Agrícola-PPGASP, Universidade do Estado de Mato GrossoUNEMAT. E-mail: <seylapessoa@gmail.com>e <brunowzago@ hotmail.com>.

${ }_{3}^{3}$ Departamento de matemática da UNEMAT. E-mail: <galvanin@ gmail.com>

${ }^{4}$ Bolsista CNPQ na UNEMAT. E-mail: <jesapk1 @ hotmail.com>

${ }^{5}$ Departamento de geografia da UNEMAT. E-mail: <ssneves@unemat.com>

${ }^{6}$ Departamento de Ciências Biológicas da UNEMAT. E-mail: < josue@ unemat.com>
} 
da fauna e flora, mudanças climáticas locais, erosão dos solos, eutrofização e assoreamento dos cursos d'água (FERREIRA; DIAS, 2004).

De acordo com Moura et al. (2010), uma bacia hidrográfica compreende diversos tributários que convergem para um curso principal e, com isso, áreas inseridas em um núcleo agrícola recebem influência na qualidade de suas águas e carregam boa quantidade de materiais derivados de atividades antrópicas, na forma de resíduos químicos ou biológicos ou sedimentos de solo pelos processos naturais como o escoamento superficial.

Nesse contexto se inserem as bacias hidrográficas como unidades básicas de planejamento para a conservação, caracterização e avaliação ambiental, pela sua importância na manutenção da vida e fragilidade derivadas das ações antrópicas (NASCIMENTO; VILAÇA, 2008).

Diante dessa problemática, a utilização de técnicas de sensoriamento remoto e geoprocessamento vêm mostrando-se promissoras, por oferecerem viabilidade e agilidade nos dados adquiridos pelas imagens orbitais (GOMES; MALDONADO, 1998), em que a resolução espacial é um dos principais fatores que permitem mapear a distribuição geográfica do uso e cobertura da terra (PONZONI; REZENDE, 2002; 2004), alcançando, assim, uma boa representação da biodiversidade com o mínimo de custo, permitindo monitorar e auxiliar os trabalhos de extensão agrícola e identificar áreas prioritárias para a conservação do meio ambiente (ANACLETO et al., 2005).

Com base no exposto, a Interbacia do Rio Paraguai Médio (IRPM) destaca-se por abranger uma área de 391.261,58 ha, que se estende ao longo do canal do rio Paraguai, cujas superfícies são geralmente planas e parcialmente alagáveis, ocupadas atualmente por extensas áreas de pastagem e monocultura de canade-açúcar (CASARIN et al., 2008).

A IRPM está contida na Bacia Hidrográfica ParaguaiJauquara (BHPJ), principal bacia situada a montante da Bacia do Alto Paraguai (BAP), que apresenta grande importância no contexto estratégico da administração dos recursos hídricos no Brasil, Bolívia e Paraguai, por incluir o Pantanal Mato-Grossense, uma das maiores extensões de áreas alagáveis do planeta (CASARIN et al., 2008) e que vem sendo afetada de forma intensa pelas atividades antrópicas localizadas nas áreas mais altas que a circunda.
Estudos sobre o uso da terra na IRPM são incipientes. Entre eles se destacam a análise da erosão marginal do rio Paraguai (SILVA et al., 2008a); os padrões do canal do rio Paraguai na região de Cáceres (SILVA et al., 2008b); o uso da terra e qualidade da água na BHPJ (CASARIN et al., 2008); e as modificações do regime de descarga do rio Paraguai Superior (GRIZIO; SOUZA-FILHO, 2010).

O objetivo deste estudo foi realizar uma análise espaço-temporal da cobertura vegetal e uso da terra na Interbacia do Rio Paraguai Médio-MT, Brasil, por meio de imagens Landsat TM, dos anos 1991, 2001 e 2011 .

\section{MATERIAL E MÉTODOS}

A área da IRPM está localizada na região Sudoeste do Estado de Mato Grosso, entre as seguintes coordenadas geográficas: $14^{\circ} 35^{\prime} 00^{\prime}$ 'S e $14^{\circ} 50^{\prime} 00^{\prime} \mathrm{S}$ e

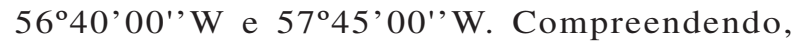
principalmente, os Municípios de Barra do Bugres, Denise e Cáceres (Figura 1).

A IRPM apresenta duas regiões fitoecológicas, a Floresta Estacional Semidecidual e a Savana, contida nos biomas Amazônia e Cerrado (BRASIL, 2004). Apresentam extensas áreas com o uso da terra por pastagens e lavouras de cana-de-açúcar (CASARIN et al., 2008). O clima da região é Tropical com regime pluviométrico composto por uma estação chuvosa, de outubro a março e, outra seca, de abril a setembro (FIETZ, 2008). O solo é composto, principalmente, por Latossolo Vermelho-Amarelo distrófico e Areias Quartzosas distróficas (BRASIL, 2001).

Para delimitação da Interbacia foram utilizadas as cartas topográficas Serra do Tira Sentido SD21ZAIV (BRASIL, 1976e), Nova Olímpia SD21 YBVI (BRASIL, 1976), Bauxi SD21ZCI (BRASIL, 1976b), Barra do Bugres SD21YDIII (BRASIL, 1976a), Rio Sepotuba SD21YDII (BRASIL, 1976c), Três Rios SD21YDV (BRASIL, 1976f) e Serra da Palmeira SD21 YDVI (BRASIL, 1976d), todas na escala de 1:100.000. As cartas foram digitalizadas, separadamente em scanner (com tamanho A3) e salvas em formato JPG com resolução de 300 dpi e transferidas para o ArcGis no módulo ArcInfo, para a vetorização das bases de dados digitais de cada carta. Em seguida, foram unidas no programa ArcMap, através do comando merge e realizado o corte pela área da bacia em estudo, utilizando o comando Clip. 
Fonte: LABGEO UNEMAT, 2012.

Source: LABGEO UNEMAT, 2012.

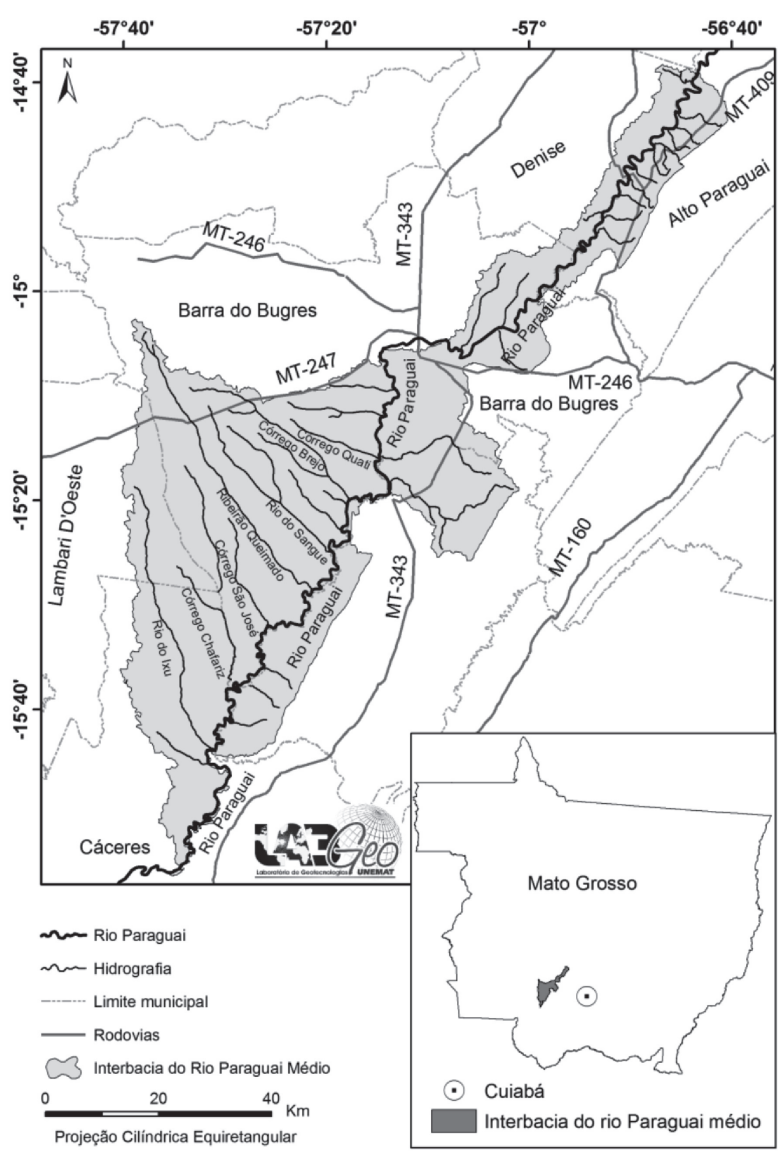

Figura 1 - Localização da área da IRPM-MT, Brasil. Figure 1 - Location of IRPM-MT, Brazil.

Para análise espaço-temporal da cobertura vegetal e uso da terra, foram adquiridas imagens do sensor TM a bordo do satélite Landsat-5, com resolução espacial de $30 \mathrm{~m}$, com órbita 227 e pontos 70 e 71, datadas de abril (período de cheia) e setembro (período de estiagem) dos anos 1991, 2001 e 2011, solicitadas a partir do catálogo de imagens do Instituto Nacional de Pesquisas Espaciais (INPE) disponível na Web.

As imagens Landsat foram processadas no software Spring, versão 5.1.7. Inicialmente, foi criado um banco de dados, utilizando-se o sistema de coordenadas UTM, datum Córrego Alegre e, fez-se o registro das imagens Landsat usando as imagens Geocover em formato GeoTiff, utilizando as bandas 3, 4 e 5 com resolução espacial de $28,5 \mathrm{~m}$, datadas de 30 de julho de 2001, no modo tela a tela.
Após o registro das imagens Landsat, efetuaramse o mosaico dos pontos 70 e 71 de cada ano e o recorte da área de estudo, através da importação da máscara da IRPM na extensão shapefile. Em seguida, realizou-se a segmentação através do método crescimento de regiões, com similaridade 10 e área de pixel 10.

Foi realizada a classificação supervisionada, feita com treinamento (atividade que consiste na identificação de amostras das classes), nas imagens do período seco, usando-se o classificador de regiões Bhattacharrya com aceitação de $99,9 \%$. Vale ressaltar que as imagens do período úmido também foram analisadas para classificação, contudo não foram mapeadas por apresentar regiões com nuvens, que proporcionam confusões espectrais.

Com a finalidade de verificar a confiabilidade do mapa gerado no Spring, foi realizada uma avaliação da exatidão, por meio do índice Kappa. Este índice considera a proporção de amostras corretamente classificadas, correspondentes à razão entre a soma da diagonal principal da matriz de erros e a soma de todos os elementos dessa matriz, representadas pelo número total da amostra, tendo como referência o número total de classes (COHEN, 1960).

Por fim, para cada ano pesquisado, as imagens classificadas foram processadas no software ArcMap, versão 9.2, no formato shapefile, para edição do mapa temático e para quantificação das classes temáticas, em uma escala de 1:1.362.000, utilizando-se a calculadora de atributos.

Foram efetuadas duas visitas na área de estudo, nas datas de 17 e 19 de fevereiro de 2012, para coleta de Pontos de Controle Terrestre (PCTs) e registros fotográficos das várias feições da região, para subsidiar a classificação das imagens de satélite.

\section{RESULTADOS}

As imagens do satélite Landsat e os levantamentos de campo permitiram identificar, mapear e quantificar sete principais classes de uso e cobertura da terra na IRPM (Figura 2). O mapa apresentado na Figura 2 teve sua acurácia verificada pela matriz de erros, usando-se o índice de concordância Kappa (Tabela 1).

No ano de 1991, os resultados apresentaram confusão espectral em relação à classe área alagável; neste caso, $13,70 \%$ dos pixels que deveriam ser atribuídos a essa classe foram aplicados erroneamente à classe

Revista Árvore, Viçosa-MG, v.37, n.1, p.119-128, 2013 

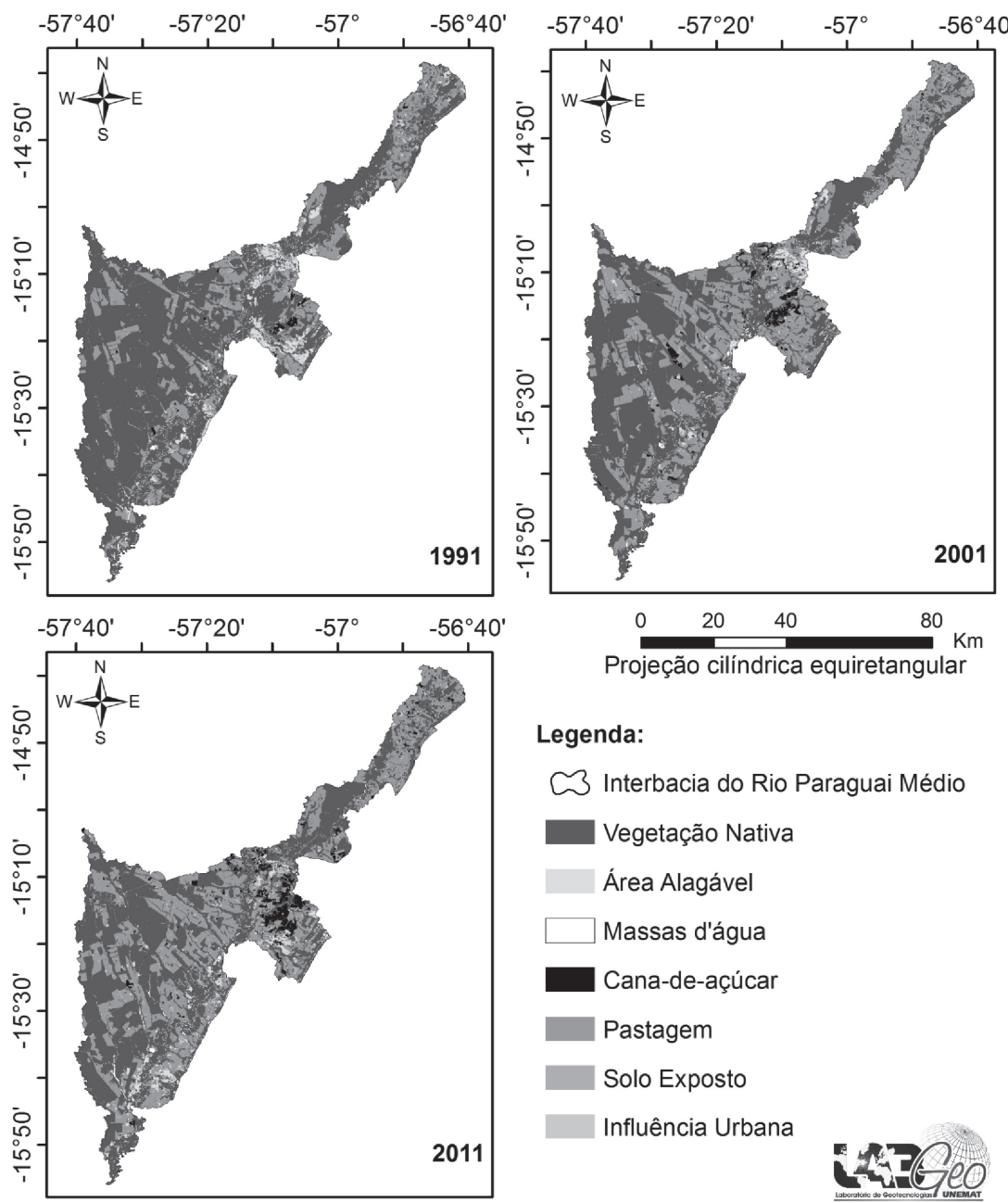

\section{Legenda:}

3 Interbacia do Rio Paraguai Médio

Vegetação Nativa

Área Alagável

$\square$ Massas d'água

Cana-de-açúcar

Pastagem

Solo Exposto

Influência Urbana

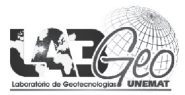

Figura 2 - Distribuição das classes temáticas do uso e cobertura da terra, na IRPM-MT, Brasil, dos anos 1991, 2001 e 2011. Figure 2 - Distribution of thematic classes of use and land cover, in the IRPM-MT, Brazil, of years 1991, 2001 and 2011.

pastagem. No ano 2001, a maior confusão espectral se deu entre as classes área alagável e solo exposto $(0,53 \%)$. No ano 2011 houve confusão espectral entre as classes solo exposto e área alagável $(8,93 \%)$ e a cana-de-açúcar com a área alagável $(2,6 \%)$.

Tabela 1 - Resultado da classificação, pelo estimador de acerto Kappa, na Interbacia do Rio Paraguai Médio-MT, Brasil.

Table 1 - Classification results based on Kappa index, of the Middle Paraguay River Interbasin-MT, Brazil.

\begin{tabular}{lrrr}
\hline & $\mathbf{1 9 9 1}$ & $\mathbf{2 0 0 1}$ & $\mathbf{2 0 1 1}$ \\
\hline Acurácia global (\%) & 99,59 & 99,87 & 99,57 \\
Índice kappa & 0,98 & 0,99 & 0,98 \\
\hline
\end{tabular}

Os resultados quantitativos das classes temáticas de cada ano pesquisado estão representados na Tabela 2 e na Figura 3.

A vegetação nativa no período analisado compõe, principalmente, as áreas de APPs ao longo do rio Paraguai, córregos Ixu e Ribeirão Queimado e as áreas de encostas das porções Norte (Alto Paraguai) e Leste da Interbacia (Figura 2). Apresentando diminuição de $19,85 \%$ de sua área em 2001 e 3,79\% em 2011 (Figura 3 e Tabela 2).

As massas de água estão situadas, principalmente: nas porções Norte e Sul da IRPM, representadas pelo rio Paraguai; pelos córrego Quati, 
córrego Brejo, rio Sangue, ribeirão Queimado e córrego São José, no Município de Barra do Bugres; e pelos córrego Chafariz e rio Ixu, no Município de Cáceres. As massas d'água apresentaram redução da área no ano 2001 de 9,20\% e aumento de 43,98\% em 2011 (Figura 2 e Figura 1).

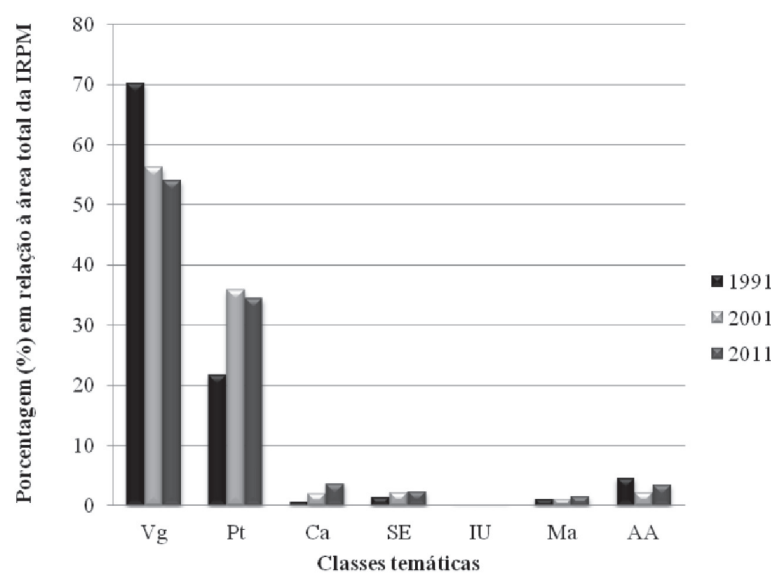

Figura 3 - Classes do uso e cobertura da terra, através de imagens Landsat-5, na Interbacia do Rio Paraguai Médio-MT, Brasil, nos anos 1991, 2001 e 2011 (IRPM); Interbacia do Rio Paraguai Médio; (Vg) Vegetação Nativa; (Ca) Cana-de-Açúcar; (Pt) Pastagem; (SE) Solo Exposto; (IU) Influência Urbana; (Ma) Massas de Águas; e (AA) Área Alagável.

Figure 3 - Use and land cover classes, using Landsat-5, in the Middle Paraguay River IInterbasin-MT, Brazil, in 1991, 2001 and 2011. (IRPM) Middle Paraguay River Interbasin; ( $\mathrm{Vg}$ ) Native Vegetation; (Ca) Sugarcane; (Pt) Grassland; (SE) Bare Soil; (UI) Urban Influence; (Ma) Water Bodies; and (AA) Floodable Area.
As áreas alagáveis apresentaram maior expressão no entorno do rio Paraguai (Figura 2), e seus resultados (Tabela 2 e Figura 3) apresentaram diminuição de 50,34\% no ano 2001 e aumento de 51,91\% em 2011.

A pastagem encontra-se localizada em toda a bacia e obteve crescimento da área em 64,88\% no ano 2001 e redução de 3,92\% no ano 2011 (Tabela 2 e Figura 3).

A cana-de-açúcar está localizada, principalmente, nas regiões Leste e Norte do Município de Barra do Bugres e próximo ao distrito de Porto Estrela (Figura 2). Apresentou aumento de $229,75 \%$ de suas áreas nos anos 2001 e $79 \%$ em 2011 (Tabela 2 e Figura 3).

O solo exposto está classificado como áreas de estradas (rodovias) e depósitos de areia dragada, presente principalmente no entorno do rio Paraguai, no Município de Barra do Bugres (Figura 2). Houve crescimento expressivo no ano 2001, de 54,25\% (Figura 3 e Tabela 2).

A influência urbana compreende áreas do Município de Porto Estrela (na região Leste da IRPM) e pesqueiros no entorno do rio Paraguai, no Município de Barra do Bugres (Figura 2). Em 1991, ocupou apenas 0,02\% da área total da interbacia, passando para $0,08 \%$ em 2011 , com aumento de $172,55 \%$ nos últimos 10 anos (Figura 3 e Tabela 2).

\section{DISCUSSÃO}

Os resultados obtidos com a utilização do estimador de acerto Kappa para a classificação realizada nos anos 1991, 2001 e 2011 são valores considerados excelentes (K > 0,8) por Foody (1992) e Congalton e Green (1998), indicando que a classificação alcançou o resultado esperado.

Tabela 2 - Classes de uso e cobertura da terra mapeadas nas imagens do satélite Landsat na Interbacia do Rio Paraguai Médio-MT, Brasil.

Table 2 - Land cover use classes mapped on the Landsat image, Middle Paraguay River Interbasin-MT, Brazil.

\begin{tabular}{lcrrr}
\hline \multirow{2}{*}{ Classes temáticas } & \multirow{2}{*}{ Legendas } & \multicolumn{3}{c}{ Área em hectares } \\
\cline { 3 - 5 } & & \multicolumn{1}{c}{1991} & \multicolumn{1}{c}{2001} & 2011 \\
\hline Vegetação nativa & $\mathrm{Vg}$ & $274.529,06$ & $220.030,25$ & $211.697,30$ \\
Pastagem & $\mathrm{Pt}$ & $85.190,20$ & $140.464,54$ & $134.955,87$ \\
Cana-de-açúcar & $\mathrm{Ca}$ & $5.504,64$ & $8.259,08$ & $14.783,95$ \\
Solo exposto & $\mathrm{SE}$ & $8.745,10$ & $8.861,54$ & $9.300,42$ \\
Influência urbana & $\mathrm{IU}$ & $4.86,06$ & 119,18 & 326,78 \\
Massas d'água & $\mathrm{Ma}$ & $18.341,33$ & $4.417,27$ & $6.359,93$ \\
Áreas alagáveis & $\mathrm{AA}$ & $\mathbf{3 9 1 . 2 6 1 , 5 8}$ & $9.109,00$ & $13.837,32$ \\
Totais & & & $\mathbf{3 9 1 . 2 6 1 , 5 8}$ & $\mathbf{3 9 1 . 2 6 1 , 5 8}$ \\
\hline
\end{tabular}


Com base na matriz de confusão e nas acurácias calculadas, pode-se afirmar que o classificador Battacharya foi capaz de classificar a maioria das regiões corretamente no período analisado. A maior confusão espectral no ano 1991 foi verificada entre a classe área alagável e a classe pastagem. A confusão espectral constatada na área alagável, solo exposto e pastagem no ano 2001 não foi representativa. Já no ano 2011 a classe área alagável apresentou 79,54\% de acurácia para usuário, nesse caso, o número de falsos-positivos foi relativamente grande nessa classe. A maior confusão espectral foi verificada na classe solo exposto, em que $8,93 \%$ dos pixels que deveriam ser atribuídos a essa classe foram atribuídos à classe área alagável.

Com relação às classes mapeadas (Figura 2) e suas quantificações (Tabela 2), de forma geral, verificou-se que nos anos 1991 e 2001 a vegetação nativa, seguida por pastagem e áreas alagáveis, foram as classes de maiores ocorrências na IRPM. No ano 2011, essa ordem mudou para vegetação nativa, pastagem e cana-deaçúcar, apresentando redução da vegetação nativa para uso agropastoril, o que indica que houve processos de antropização na vegetação nativa, principalmente em 2001 .

As práticas de manejo tradicionalmente desenvolvidas na pastagem e cana-de-açúcar, localizadas na vizinhança da vegetação nativa na IRPM (Figura 2), podem influenciar na alteração da fauna e flora da região, pois, segundo Nascimento et al. (2006), o uso de agroquímicos, queimadas para "limpeza do terreno", poluição sonora resultante das movimentações de máquinas e veículos motorizados, deposição excessiva de particulados na vegetação dos remanescentes e produção de lixo, ligados às atividades agropastoris, proporcionam, sobretudo, o afugentamento de animais ou impedimento da locomoção de espécies dispersoras.

Os resultados da vegetação nativa também podem ser relacionados com os dados do Instituto Brasileiro de Geografia e Estatítica - IBGE (2008), que apresentam a supressão da vegetação nativa no Estado de Mato Grosso ligada à expansão de cultivos agrícolas e criações de alto retorno econômico, como é o caso da cana-deaçúcar e da pastagem, sendo esses cultivos favorecidos por estarem adaptados às condições edafoclimáticas da região (FIETZ et al., 2008; TOLEDO et al., 2011).

A substituição da vegetação nativa pela criação de gado e pelo desenvolvimento da agricultura vem provocando intensos desmatamentos e queimadas, causando graves danos ambientais por todo o Brasil, como demonstrado nos trabalhos realizados na Amazônia Legal sobre as mudanças na paisagem, ocupação e uso da terra, desenvolvidos por Fearnside (2005), Warker e Homma (1996), Durieux et al. (2003), Vosti et al. (2003), Chust et al. (2004), Desjardins (2004), Anacleto et al. (2005), Ferraz et al. (2005) e Kirby et al. (2006).

Em relação à conexão entre a IRPM e a BAP, a degradação ambiental decorrente da exploração econômica presente na unidade de estudo representa séria ameaça, principalmente, aos ecossistemas das áreas situadas a sua jusante, afetando todo o Pantanal Mato-Grossense, sobretudo, pela presença de pesticidas associada às atividades agrícolas que ocupam áreas que deveriam ser mantidas como mata ciliar, próximos aos rios e córregos da IRPM (CASARIN et al., 2008).

Toledo e Niconella (2002) e Vanzela et al. (2010) afirmaram que a qualidade da água está extremamente ligada com o tipo de uso e ocupação da terra ao seu redor, verificando em seus estudos que houve aumento na concentração dos sólidos e redução de pH na água, relacionados com a presença de áreas agricultáveis (culturas perenes, culturas perenes irrigadas e culturas anuais), habitadas (área urbana e moradias rurais) ou em matas degradadas.

A classe pastagem é a forma de uso da terra mais expressiva em todos os anos e encontra-se espalhada por toda a IRPM, apresentando crescimentos no sentido Leste para Oeste, principalmente próximos aos cursos de água. Sua diminuição observada em 2011 está ligada à substituição de algumas áreas da porção Norte e Leste do Município de Barra do Bugres, para o cultivo da monocultura de cana-de-açúcar (Figura 2).

Os resultados apresentados na classe pastagem estão de acordo com as análises de Casarin et al. (2008), que afirmaram que a expansão de áreas de pastagem, na IRPM, estão relacionadas à necessidade do aumento de áreas para essa atividade, gerada pelo crescimento do "consumo econômico" da região.

A presença de extensas áreas de pastagem e crescimentos de suas áreas próximas aos cursos de água constitui fator negativo, por impactar, de diversas maneiras, na conservação do ambiente e biodiversidade da interbacia, tendo como prejuízo principal o desmatamento da vegetação nativa, aumento da erosão e compactação do solo através do pisoteio dos animais 
e contaminação das águas na utilização de agroquímicos como nutrientes e pesticidas, em suas atividades (NOVOTNY; OLEM, 1993).

Nesse contexto, vale ressaltar que, de acordo com Brossard e Barcelos (2005), a produção pecuária no Cerrado, particularmente a de gado de corte, passou rapidamente do manejo de recursos forrageiros da savana herbácea e arbórea, como fonte de alimento para o gado, à exploração dos recursos de pastagens cultivadas nos últimos 40 anos.

Diante dos resultados da classe cana-de-açúcar, é possível afirmar que ela representa a segunda classe de uso da terra mais expressiva na IRPM, e seu crescimento foi impulsionado, principalmente, pela existência e desenvolvimento da usina Barralcool, localizada no Município de Barra do Bugres e usina Itamarati, localizada no Município de Nova Olímpia (CASARIN et al., 2008).

Essas usinas tiveram sua origem em 1980, incentivadas pelo Programa Nacional de Álcool (Proálcool) e efetuaram sua primeira safra em 1983. A Itamarati realizou um cultivo de sete mil hectares, com capacidade para produzir $150.000 \mathrm{~L}$ de etanol por dia e avançou para, aproximadamente, $5.400 .000 \mathrm{~L}$ atualmente (SEGLIN, 2010) e a Barralcool que produziu 58.134 toneladas na primeira safra aumentou para 2.028.257 toneladas na safra 2010/2011 (BARRALCOOL, 2012).

Ainda vale ressaltar que o Estado de Mato Grosso possui destaque na produção da cultura de cana-deaçúcar, representando atualmente $2,2 \%$ da produção brasileira, obtendo avanços significativos na safra 2010/ 2011, na qual produziu 13.835,1 toneladas plantadas em 207,05 mil hectares e, consequentemente, aumentou em $10,7 \%$ a produção de açúcar e 4,27\% de etanol em relação à safra anterior (CONAB, 2011).

A cultura de cana-de-açúcar em 2011, na IRPM, se deu pela substituição de algumas áreas utilizadas por pastagem em 1991. Esses resultados estão de acordo com o Censo Agropecuário de 2005-2006, que demonstrou um aumento de 83,5\% nas áreas de lavouras do país, em relação ao Censo de 1995-1996, enquanto as áreas ocupadas pelas pastagens reduziram em aproximadamente $3 \%$, confirmando um modelo de desenvolvimento do setor com expansão das fronteiras agrícolas e substituição das áreas de pastagem por lavouras, em razão da progressiva inserção do país no mercado mundial de produção agrícola (IBGE, 1998 e 2008). Estudos realizados por Simões (2009) também verificaram essa tendência.

Segundo Politano et al. (1983), Barros et al. (1987) e Campos et al. (1993), a expansão canavieira no Estado de Mato Grosso foi estabelecida, principalmente, em áreas deixadas por outras culturas e influenciadas por incentivos governamentais desde a década de 1970. De acordo com Cardoso et al. (1992), além dos incentivos governamentais, a expansão dessas áreas também foi provocada pela necessidade de buscar fontes alternativas de energia para produção de biomassa.

A classe solo exposto e a influência urbana caracterizaram-se como as menores expressões territoriais na área de estudo.

\section{CONCLUSÃO}

A utilização das imagens Landsat-5 permitiu a identificação e elaboração do mapeamento temático de sete classes de uso e cobertura da terra na IRPM, sendo elas: a vegetação nativa, pastagem, cana-deaçúcar, massas d'água, áreas alagáveis, solo exposto e influência urbana.

A vegetação nativa sofreu intensos processos de antropização na área de estudo nos últimos 20 anos, principalmente pela substituição de cerca de $22,89 \%$ de sua área de ocorrência, para uso da terra como pastagem e como monocultura de cana-de-açúcar, em 2001. A expansão da monocultura de cana-de-açúcar ocorreu em área de pastagem e, principalmente, próximas às usinas.

As constatações verificadas na unidade de estudo estão diretamente relacionadas com o estado de conservação do bioma Pantanal Mato-Grossense, por afetar essas áreas com possíveis contaminações na água, influenciadas pelo uso da terra e desmatamento indevido das matas ciliares do entorno do rio Paraguai, na IRPM.

Os mapas de uso da terra gerados para área de estudo podem ser utilizados pelos órgãos governamentais com poder de fiscalização, para identificar e localizar as áreas que estão em conflito de uso da terra, viabilizando, de maneira sem precedentes, a aplicação do Código Florestal.

Revista Árvore, Viçosa-MG, v.37, n.1, p.119-128, 2013 


\section{AGRADECIMENTOS}

À Coordenação de Aperfeiçoamento de Pessoal de Nível Superior (CAPES), pelo apoio em forma de bolsa de mestrado.

\section{REFERÊNCIAS}

ANACLETO, T. C. S. et al. Seleção de áreas de interesse ecológico através de sensoriamento remoto e de otimização matemática: um estudo de caso no município de Cocalinho, MT. Acta Amazônica, v.35, n.4, p.437-444, 2005.

BARRALCOOL. Números da safra 2011. Grupo Barralcool. [2012] Disponível em: < http:// barralcool.com.br/?p=562 >. Acesso em: 22 fev. 2012 .

BARROS, Z. X.; CARDOSO, L. G.; TARGA, L. A. Utilização de fotografias aéreas em ocupação do solo por cobertura vegetal. In: CONGRESSO BRASILEIRO DE ENGENHARIAAGRÍCOLA, 16., 1987, Jundiaí. Anais... Jundiaí: SBEA, 1987. p.598-603.

BIERREGAARD JÚNIOR, R. O. et al. The biological dynamics of tropical rainforest fragments a prospective comparasion of fragment and continuous forest. Bioscience, v.42, n.11, p.859-866, 1992.

BRASIL. Ministério da Integração Nacional. Mapa de solos do Estado de Mato Grosso. Mato Grosso: SEPLAN, 2001. Mapa color. Escala 1:250.000. Disponível em: <http:// www.zsee.seplan.mt.gov.br/mapaspdf/A001\%20\% 20Mapa\%20de\%20Solos\%20do\%20Estado\%20de\%20 Mato\%20Grosso.pdf> Acesso em: 20 de fev. 2012.

BRASIL. Ministério do Exército. Nova Olímpia (SD21YBVI). Rio de Janeiro: Diretoria de Serviços Geográficos, 1976c. Carta, color., $79 \mathrm{~cm}$ x $95 \mathrm{~cm}$.

BRASIL. Ministério do Exército. Barra do Bugres (SD21YDIII). Rio de Janeiro: Diretoria de Serviços Geográficos, 1976a. Carta, color., $79 \mathrm{~cm}$ x $95 \mathrm{~cm}$. Escala 1:100.000.

BRASIL. Ministério do Exército. Bauxi (SD21ZCI). Rio de Janeiro: Diretoria de Serviços Geográficos, 1976b. Carta, color., 79 cm x $95 \mathrm{~cm}$. Escala 1:100.000.
BRASIL. Ministério do Exército. Rio Sepotuba (SD21YDII). Rio de Janeiro: Diretoria de Serviços Geográficos, 1976c. Carta, color., 79 cm x $95 \mathrm{~cm}$. Escala 1:100.000.

BRASIL. Ministério do Exército. Serra da Palmeira (SD21YDVI). Rio de Janeiro: Diretoria de Serviços Geográficos, 1976d. Carta, color., $79 \mathrm{~cm}$ x $95 \mathrm{~cm}$. Escala 1:100.000.

BRASIL. Ministério do Exército. Serra do Tira Sentido (SD21ZAIV). Rio de Janeiro: Diretoria de Serviços Geográficos, 1976e. Carta, color., $79 \mathrm{~cm}$ x $95 \mathrm{~cm}$. Escala 1:100.000.

BRASIL. Ministério do Exército. Três Rios (SD21YDV). Rio de Janeiro: Diretoria de Serviços Geográficos, 1976f. Carta, color., 79 cm x $95 \mathrm{~cm}$. Escala 1:100.000.

BRASIL. Ministério do Meio Ambiente e Instituto Brasileiro de Geografia - IBGE. Mapa de Biomas do Brasil (primeira aproximação). Rio de Janeiro: 2004. Mapa color. Escala 1: 500.0000 .

BROSSARD, M.; BARCELLOS, E. A. O. Conversão do cerrado em pastagens cultivadas e funcionamento de Latossolos. Cadernos de Ciência e Tecnologia, v.22, n.1, p.153-168, 2005.

CAMPOS, S. et al. Agrupamentos das Divisões Regionais Agrícolas com relação à cobertura vegetal do Estado de São Paulo, em 1990. In: CONGRESSO BRASILEIRO DE ENGENHARIA AGRÍCOLA, 22., 1993, Ilhéus. Anais... Ilhéus: SBEA/CEPLAC, 1993. p.329-338.

CARDOSO, L. G.; PIEDADE, G. C. R.; BARROS, Z. X. Implantação de canaviais em Latossolo Roxo (LR) e o comportamento do processo erosivo analisado em bacias hidrográficas de $3 \mathrm{a}$ ordem de ramificação. Científica, v.20, n.1, p.119-128, 1992.

CASARIN, R.; NEVES, S. M. A. S.; NEVES, R. J. Uso da terra e qualidade da água da Bacia hidrográfica Paraguai/Jauquara-MT. Revista Geográfica Acadêmica, v.2, n.1, p.33-42, 2008.

CHUST, G.; DUCROT, D.; PRETUS, J. L. I. Land cover mapping with patch-derived landscape índices. Landscape and Urban Planning, v.69, n.2204, p.437-449, 2004. 
COHEN, J. A. Coefficient of agreement for nominal scales. Educational and Psychological Measurement, v.20, n.1, p.37-46, 1960.

\section{COMPANHIA NACIONAL DE ABASTECIMENTO}

- CONAB. Acompanhamento de safra brasileira: cana-de-açúcar, terceiro levantamento, janeiro/2011. Brasília: 2011. Diponível em: <http://www.conab.gov.br/ OlalaCMS/uploads/arquivos/ 11_01_06_09_14_50_boletim_cana_ 3o_lev_safra_2010_2011.pdf $>$. Acesso em: $20 \mathrm{de}$ set. 2011.

CONGAlton, R. G.; GREEN, K. Assessing the accuracy of remotely sensed data: principles and practices. New York: Lewis Publishers, 1998. 137p.

DESJARDINS, T. et al. Effects of forest conversion to pasture on soil carbon content and dynamics in Brazilian Amazonia.

Agriculture Ecosystems e Environment, v.103,p.365-373, 2004.

DURIEUX, L.; MACHADO, L. A. T.; LAURENT, $H$. The imapact of deforestation on cloud cover over the Amazon arc of deforestation. Remote Sensing of Environment, v.86, n.2003, p.132-140, 2003.

FEARNSIDE, P. M. Desmatamento na Amazônia Brasileira: história, índices e consequências. Megadiversidade, v.1, p.115-123, 2005.

FERRAZ, S. F. B. et al. Landscape dynamics of amazonian deforestation between 1984 and 2002 in central Rondônia, Brazil: assess smente and futur scenarios. Forest Ecology and Management, v.204, n.1, p.67-83, 2005.

FERREIRA, D. A. C.; DIAS, H. C. T. Situação atual da mata ciliar do ribeirão São Bartolomeu em Viçosa, MG. Revista Árvore, v.28, n.4, p.617623, 2004.

FIETZ, C. R. et al. Estimativa da precipitação provável para o Estado de Mato Grosso. Dourados: Embrapa Agropecuária Oeste, 2008.
FOODY, G. M. On the compensation for chance agreement in image classification accuracy assessment. Photogrametric

Engineering and Remote Sensing, v.58, n.10, p.1459-1460, 1992.

GOMES, A. R.; MALDONADO, F. D. Análise de componentes principais em imagens multitemporais TM/Landsat como subsídio aos estudos de vulnerabilidade à perda de solo em ambiente semi-árido. In: SIMPÓSIO BRASILEIRO DE SENSORIAMENTO REMOTO, 9. (SBSR), 1998, Santos. Anais... São José dos Campos: INPE, 1998. p.959-968. CD ROM.

GREGGIO, T. C.; PISSARRA, T. C. T.; RODRIGUES, F. M. Avaliação dos fragmentos florestais do município de Jaboticabal-SP. Revista Árvore, v.33, n.1, p.117-124, 2009.

GRIZIO, E. V.; SOUZA FILHO, E. E. As modificações do regime de descarga do rio Paraguai Superior. Revista Brasileira de Geomorfologia, v.11, n.2, p.25-33, 2010.

INSTITUTO BRASILEIRO DE GEOGRAFIA E ESTATÍSTICA - IBGE. Censo Agropecuário 1995/1996 - Brasil. Rio de Janeiro: 1998. p.94. Disponível em: < http://www.ibge.gov.br/ home/estatistica/economia/agropecuaria/ censoagro/1995_1996/default.shtm > Acesso em: 20 de mar. 2012.

INSTITUTO BRASILEIRO DE GEOGRAFIA E ESTATÍSTICA - IBGE. Censo Agropecuário 2006 - Brasil (Dados preliminares). Rio de Janeiro: 2008. p.1-146. Disponível em: < http:// www.ibge.gov.br/home/estatistica/economia/ agropecuaria/censoagro/2006/agropecuario.pdf> Acesso em: 20 de mar. 2012.

KIRBY, K. R et al. The future of deforestation in the Brasilian Amazon. Futures, v.38, p.432-453, 2006.

MOURA, L. H. A.; BOAVENTURA, G. R.; PINELLI, M. P. A qualidade de água como indicador de uso e ocupação do solo: Bacia do Gama, Distrito Federal. Quimica Nova, v.33, n.1, p.97-103, 2010.

NASCIMENTO, M. C. et al. Mapeamento dos fragmentos de vegetação florestal nativa da bacia hidrográfica do Rio Alegre, Espírito Santo, a partir de imagens do satélite IKONOS II. Revista Árvore, v.30, n.3, p.389-398, 2006.

Revista Árvore, Viçosa-MG, v.37, n.1, p.119-128, 2013 
NASCIMENTO. W. M.; VILAÇA, M. G. Bacias hidrográficas: planejamento e gerenciamento. Três Lagoas: Associação dos Geógrafos Brasileiros, 2008. n.7.

\section{NOVOTNY, V.; OLEM, H. Water quality:} prevention, identification and management of diffuse pollution. New York: Van NostrandReinhold, 1993.

POLITANO, W. et al. Caracterização por fotointerpretação da ocupação do solo no município de Monte Alto-SP. Revista de Engenharia Agrícola, v.7, n.1, p.17-25, 1983.

PONZONI, F. J.; REZENDE, A. C. P. Caracterização espectral de estágios sucessionais de vegetação arbórea secundária arbórea em Altamira (PA), através de dados orbitais. Revista Árvore, v.28, n.4, p.535-545, 2004.

PONZONI, F. J.; REZENDE, A. C. P. Influência da resolução espacial de imagens orbitais na identificação de elementos da paisagem em AltamiraPA. Revista Árvore, v.26, n.4, p.403-410, 2002.

SEGLIN, J. Usinas Itamarati: 30 anos de ousadia. Usinas Itamarati S/A, Nova Olímpia-Mato Grosso, n. 33, dez. 2010. Disponível em: <http:// www.usinasitamarati.com.br/itamarati/images/ dez10.pdf> . Acesso em: 10 fev. 2012.

SILVA, A.; NEVES, A. M. A. S.; NEVES, R. J. Sensoriamento remoto aplicado ao estudo da erosão marginal do rio Paraguai: Bairro São Miguel em Cáceres/MT-Brasil. Revista Geográfica Acadêmica, v.2, n.3, p.19-27, 2008a.
SILVA, E.; SOUZA FILHO, E. E.; CUNHA, S. B. Padrões de Canal do Rio Paraguai na região de Cáceres (MT). Revista Brasileira de Geociências, v.38, n.1, p.169-179, 2008 b.

SIMÕES, J. Estudo inédito, com base em imagens de satélite, mostra avanço sobre pastagens e outros cultivos; florestas são pouco atingidas. Inovação Unicamp, 31 ago. 2009.

TOLEDO, A. M. A. et al. Determinação da aptidão edafoclimática da cana-de-açúcar no pólo regional de Rondonópolis - MT. Enciclopédia Biosfera, Centro Científico Conhecer, v.7, n.13, p.381-399, 2011.

TOLEDO, L. G.; NICONELLA, G. Índice de qualidade de água em microbacia sob uso agrícola e urbano. Scientia Agricola, v.59, n.1, p.181-186, 2002.

VANZELA, L. S.; HERNANDEZ, F. B. T.; FRANCO, R. A. M. Influência do uso e ocupação do solo nos recursos hídricos do córrego Três Barras, Marinópolis. Revista Brasileira de Engenharia Agrícola e Ambiental, v.14, n.1, p.55-64, 2010.

VOSTI, A. S. et al. Rights to forest products, deforestation and smallholder income: evidence from the Westem Brazilian Amazon. World Development, v.31, n.11, p.1889-1901, 2003.

WARKER, R.; HOMMA, A. K. O. Land use and cover dynamics in the Brazilian Amazon: na overview. Ecological Economics, v.18, n.1, p.6780, 1996. 